\title{
Comentário a “O Ensino e a Pesquisa em HistóRIA ANTIGA NO BRASIL: REFLEXões A PARTIR DOS DADOS DA PlatAFORMA LATTES” DE DOMINIQUE SANTOS, GraZiele KolV E JULIANO JoÃo NAZÁRIO
}

Luís Ernesto Barnabé ${ }^{1}$

O trabalho de Dominique Santos, Graziele Kolv e Juliano João Nazário (doravante S.K.N.) tem o mérito de apresentar de maneira consistente aquilo do que os profissionais da área já tinham conhecimento intuitivo, mas não sistematizado: a história antiga produzida no Brasil, com vivacidade, se mantém constante e as especificidades de seu estudo não são fatores que impedem a sua realização.

O esforço para oferecer uma análise sistemática do ensino e da pesquisa em História Antiga no Brasil a partir da Plataforma Lattes deve ser muito bem-vindo, pois possibilita o pensarmos tal produção acadêmica como um objeto historicamente constituído em meio a embates no campo do Ensino Superior e sua expansão pelo território brasileiro. A formação de gerações de pesquisadores tornou-se consistente, a partir dos programas de pós-graduação, inicialmente em São Paulo e no Rio de Janeiro, e em seguida em franca expansão por diversos Estados, além das oportunidades de internacionalização, seja para formação ou mesmo participação em eventos, o que insere a produção nacional no cenário global de pesquisas.

Ao definir a história como indissociavelmente social e cultural, Antoine Prost (2008, p. 14) chama a atenção para as relações que os historiadores estabeleceram ora com o campo, simultaneamente científico e social, ora com a própria sociedade "em seu conjunto e em seus segmentos que, afinal, são os destinatários de seu trabalho e para quem essa história tem, ou não, sentido”. E será a partir deste caminho que nortearemos as discussões que se seguirão. Nesse sentido, se nos atentarmos para as relações estabelecidas com o próprio campo, o artigo possibilita dimensionar a tensão que se estabelece quando são colocados lado a lado a produção de História Antiga brasileira e o posicionamento ou interesse/conhecimento de outros historiadores brasileiros, integrantes de

\footnotetext{
${ }^{1}$ Professor do curso de História da UENP. Doutorando da UNESP-Assis.
} 
departamentos e colegiados nas universidades, em relação à História Antiga. Na maioria das vezes se desconhece o debate e é comum ouvirmos de colegas concepções de que a História Antiga é eurocêntrica e pouco contribui para (ou atrapalha) a formação da identidade nacional, ou ainda que o distanciamento temporal e espacial não faria sentido para a escolarização de crianças.

Acertadamente $o$ artigo chama a atenção para que mesmo com as produções classificadas a partir das formas tradicionais - Grécia, Roma, Egito, Oriente, mais por uma questão da própria estrutura da plataforma Lattes (e possivelmente da definição que é senso comum dos que a acessam), isso não significa que os pesquisadores brasileiros não participem das constantes revisões conceituais decorrentes a partir da segunda metade do século XX, que promoveram uma ampliação de ferramentas, olhares e questões, e consequentemente, constituíram novos objetos e categorias interpretativas do Mundo Antigo: "Mediterrâneo Antigo", "Diálogos entre História e Arqueologia Provincial”, “A Cultura Material no Império Romano", “Arqueologia Clássica” etc.

Dentro dessa mesma tensão há ainda a que considerarmos a junção de história antiga e medieval em muitos concursos e cadeiras de universidades - o que ignora as especificidades de cada uma, como já sugeria Eurípedes Simões de Paula em 1961; bem como a ausência em muitas universidades de docente com formação na área, o que acarreta em cursos muitas vezes com bibliografia e abordagem já superadas e, consequentemente, impactos sérios na atuação do futuro docente na Educação Básica. Ainda sobre esta questão, os apontamentos sobre a predominância do "Ocidente" Antigo ante ao "Oriente" são importantes, e as práticas docentes na graduação são um fator da manutenção de tal situação, na medida em que são pouco abordados como conteúdos e menos escolhidos para temas de trabalhos de conclusão de curso, iniciação científica, ou mesmo pós-graduação.

Caberia aqui a pergunta: a incidência de estudos brasileiros acerca da “Antiguidade Oriental” tem aumentado ou diminuído desde o início do século XXI?, embora a resposta somente fosse possível a partir de uma reorganização dos dados levantados. Outra questão que a pesquisa de S.K.N. provoca é como a produção nacional de História Antiga tem sido utilizada nos cursos de graduação brasileiros (o que, dependendo da boa vontade dos docentes nas universidades públicas, poderia 
ser feito a partir de uma amostragem muito próxima da totalidade), e/ou ainda, já reconhecendo a necessidade de limite na coleta de dados, por professores da rede básica de ensino.

Mas é, sobretudo acerca do segundo ponto de Prost (2008), ou seja, a relação dos historiadores (e da História Antiga especificamente) com a sociedade, que dedicarei maior espaço para comentários. As relações entre História Antiga e a sociedade brasileira, em um processo complexo e não de via única, por meio de práticas, representações apropriações, usos do passado, constituição de memória, têm sido meu interesse de pesquisa nos últimos anos (Barnabé, 2015).²

Foi no bojo dos projetos de modernidade empreendidos pelos Estadosnacionais ao longo do século XIX que surgiram espaços e criaram-se carreiras para profissionais atuarem na educação (ensino) e na ciência (pesquisa), e especificamente para esta discussão, ocorre a disciplinarização da História. No caso francês (Prost, 2008, p. 16),

O ensino da história emancipou-se, progressivamente, da tutela das humanidades para conquistar sua autonomia e avançar até a época contemporânea, ao passo que a compreensão panorâmica de ordem política e social acabou substituindo a memorização das cronologias e a enumeração dos reinos. Esta dupla evolução dos conteúdos e métodos deveuse, em grande parte, à especialização progressiva dos professores de história: o princípio de um professor especial foi estabelecido, em 1818 - e confirmado, em 1830 pela criação de uma agrégation de história que permitiu formar e contratar um pequeno núcleo de historiadores qualificados. Sua supressão pelo Império autoritário, durante o curto período de 1853 a 1860, não chegou a comprometer a constituição do corpo de docentes de história.

Da condição de acessório dos estudos de latim e grego, o trato com o passado ganha novos contornos com professores especializados, e os textos clássicos tornamse fontes históricas. Consolidar-se-ia ao longo do século XIX um saber autônomo, com questões heurísticas, disciplinares, profissionais.

\footnotetext{
2 Em 2015, iniciei pesquisa para obtenção do título de doutorado que analisa os manuais escolares de História Antiga do século XIX e início do XX. Em novembro de 2016, apresentei a comunicação: "Justiniano José da Rocha e os Primeiros Manuais de História Antiga na Escolarização" no IX Encontro do GTHA, realizado no Museu Nacional, Rio de Janeiro.
} 
Destacamos aqui (embora isso possa parecer injusto com os demais) três nomes para ilustrar questões de profissionalização da carreira, do desenvolvimento de pesquisa histórica e/ou método e ocupação de um espaço recém-criado - o mercado de manuais escolares: Victor Duruy, que nos anos de 1830 já era um renomado professor do secundário e autor de Histoire des Romains et des peuples soumis à leur domination, em sete volumes (1843-1844), e do manual escolar Compêndio de Historia Universal3 (traduzido no Brasil em 1865 pelo padre Francisco Bernardino de Souza), e depois ministro da instrução pública nos anos de 1860; Fustel de Coulanges, 4 que inicia sua carreira publicando pesquisas acerca de Vesta e Políbio (ambas de 1858), como docente do ensino superior em Estrasburgo publica a Cidade Antiga (em 1864) e termina seus dias buscando compreender a França: Histoire des institutions politiques de l'ancienne France, projeto que abarcaria da Gália romana a 1789, mas com apenas a publicação de dois dos quatro volumes pretendidos; e finalmente Charles Seignobos, do qual destacaríamos o manual escolar Histoire de la Civilisation, cujo primeiro volume é de 1893 , que também será traduzido e muito difundido no Brasil até as primeiras décadas do século XX, e o famigerado Introduction aux êtudés históriques (de 1898), produzido em parceria com Charles Victor Langlois.

A opção de nossa argumentação iniciar pela França se justifica pelas menções feitas acima ao Brasil no campo educacional. Rodrigo Turin (2015, p. 306307) comenta da falta de estudos acerca das transferências de regulamentos e materiais didáticos da França ao Brasil, mas acena para duas homologias que tornam inteligível esse trânsito: apesar das diferenças entre as políticas educacionais dos dois países, havia em comum o interesse em produzir uma elite letrada

3 Circe Bittencourt (2008) menciona o Manuel Du Baccalauréat, de 1855, entre os livros adotados no Colégio Pedro II, que provavelmente trata-se do Nouveau manuel du baccalauréat és lettres histoires ancienne, Du moyen age et des lês temps modernes, réedigé conformément aux programmes de 1852. Paris: L. Hachette, 1853 de Duruy.

4 Em seu caso Fustel, François Hartog (2003) analisa a preocupação de Fustel quanto ao método, a relação com o passado, e novamente enfatizamos, em um momento sem que os procedimentos do campo estivessem definidos e muito do que se produz resulta de autodidatismo. Fustel não defende o regime moderno de historicidade, mas sua obra demonstra que o antigo regime da historia magistra vitae já não é possível. O passado não esclarece o futuro. E finalmente, não há patriotismo, mas ciência e conhecimento. O que não impede que o historiador tenha um papel nitidamente social. É o pontífice entre o passado da França e seu presente - explicar o vínculo lógico que liga todos os períodos do desenvolvimento do país. Trata-se de análise, não síntese (Hartog, 2003, p. 25-26). 
minimamente homogênea e ligada ao Estado, evitando os perigos da liberdade e da fragmentação do ensino; outra seria a forte expectativa de consolidação de uma ordem social após períodos de conturbações políticas e semânticas - no caso francês terminar a revolução, no caso brasileiro a estabilização política e social pós I Reinado e período regencial.

Assim, mirando na França, não como parâmetro, mas como uma referência, a partir do processo descrito acima, a produção de História Antiga (francesa) encontra-se consistente com a acepção de história enquanto ciência em vigor no século XIX (arriscaríamos a dizer que mais precisamente, a partir da segunda metade século). E no caso brasileiro é notória a inviabilidade da questão da expansão da escolarização que resulta na formação de profissionais cada vez mais especializados e espaços institucionais para o desenvolvimento de atividades de pesquisa.5 Para ficarmos em um caso, Justiniano José da Rocha, advogado por formação, jornalista político vinculado a Bernardo Vasconcellos e aos saquaremas, tem a oportunidade de lecionar história, pela primeira vez no país em moldes institucionais, no Colégio Pedro II. Traduz compêndios franceses em 1840 e produz seu próprio compêndio em 1860 . De certa maneira, aí está a criação da disciplina escolar de história (que até a Reforma Couto Ferraz, de 1854, valorizava muito mais a História Antiga e a história romana do que as outras histórias).

Tudo isso nos suscita uma série de perguntas, que as lanço mais como exercício reflexivo, uma vez que não se trata do objeto do artigo em questão. Qual seria o lastro da disciplina? Justiniano faz pesquisas como Fustel de Coulanges ou simplesmente copia, sintetiza, interpreta compêndios europeus? Qual seu limite interpretativo do passado perante as explicações dadas nas obras que consulta acerca de algum episódio como a guerra entre Esparta e Atenas, ou a morte de César, ou as invasões bárbaras? E qual o limite dessa liberdade ante as regulamentações curriculares que acabam por definir o que deve e o que não deve constar nos manuais escolares?

\footnotetext{
5 Mesmo que consideremos o IHGB, suas particularidades por ser um espaço restrito, regulamentado por critérios que passam necessariamente pela teia das relações sociais e pessoais, como salienta Manoel Guimarães (1988, p.60) - o que não significa que não tenha havido contatos com as inovações e avanços na historiografia brasileira, mas que quando ocorria era por conta mais de autodidatismos que ações institucionais.
} 
Nas subsequentes reformas curriculares e na publicação de autores franceses é possível ver como a forma da História Antiga da educação secundária ganha novos contornos, e é por isso que acima mencionamos o compêndio de Seignobos. Só para ilustrarmos rapidamente algumas diferenças entre as duas obras: o início da humanidade no compêndio de Justiniano se dá com a criação bíblica, enquanto que Seignobos inicia com o conceito de pré-história; os capítulos de Seignobos são organizados por povos: 1 . Os povos do Oriente; 2. Os gregos; 3. República romana; 4. Império Romano; 5. Germanos; sendo os romanos os únicos que detêm dois capítulos, ao passo que na obra de J. Rocha encontramos 39 capítulos curtos (que podem variar de duas a quinze páginas), em uma narrativa universal da humanidade. Gostaríamos de frisar rapidamente dois pontos. Justiniano Rocha intitula seu compêndio de "História Universal", ao passo que Seignobos, "História das Civilizações”. A própria organização dos assuntos demonstra esta diferença conceitual - para Seignobos, a humanidade se forma a partir das civilizações. Ademais, o espaço dedicado a Roma é proporcionalmente semelhante nas duas obras, tal como o é boa parte dos livros didáticos atuais, e pelo que a pesquisa de S.K.N. mostrou, também está presente na produção brasileira de História Antiga.

E para finalizar, no início do artigo de S.K.N, encontramos as terminologias: (a presença da) tradição clássica, (o estudo da) Antiguidade e (criou-se uma disciplina totalmente dedicada à) História Antiga. Por mais próximas que possam parecer, há uma historicidade implícita em cada uma, e apesar de tratarem da mesma temática - o passado restrito àquela temporalidade e espacialidade - não são a mesma coisa. Devemos salientar que o interesse em se fazer uso ou transmitir esse passado é significativo (pelos jesuítas ou pelo governo brasileiro do século XIX), da mesma maneira que foram desenvolvidos modos de se fazê-lo. É inegável o uso da Antiguidade Clássica pelos países europeus na constituição de suas identidades, o fato de estas estarem ligadas ao conceito de Cultura Ocidental em oposição ao Oriente e, finalmente, que tal formatação predomina em boa parte dos currículos escolares, mesmo em países não europeus - como S.K.N. salientam, apoiados em Maria Florenzano (2008), Pedro Paulo Funari e Renata Garraffoni (2004) e Guarinello (2004), respectivamente. 
Sendo assim, lidar com a "disciplina totalmente dedicada à História Antiga" (em 1849, no Colégio Pedro II) e com a História Antiga cujo ensino e pesquisa podem ser analisados a partir da Plataforma Lattes é oportuno desafio que sugere o cuidado de não se tomar como partida a ideia de hierarquização dos saberes da História Acadêmica sobre a História Escolar, como tentamos demonstrar acima e como S.K.N. chamam a atenção nas considerações finais. Como salienta Norberto Guarinello (2013), para o bem ou para o mal, a história antiga nos ocidentaliza e isso decorre da construção de uma memória social, graças ao processo de escolarização da sociedade brasileira. 


\section{Referências Bibliográficas:}

Barnabé, L. E. De olho no presente: História Antiga e livros didáticos no século XXI. OPSIS (Catalão-GO), vol. 14, n. 2, 2014, p. 114-132.

Bittencourt, C. M. F. Livro didático e saber escolar (1810-1910). Belo. Horizonte: Autêntica, 2008.

Guarinello, N. L. História Antiga. São Paulo: Contexto, 2013.

Hartog, François. O Século XIX e a História: O Caso Fustel de Coulanges. Rio de Janeiro: Editora UFRJ, 2003.

Prost, Antoine. Doze lições sobre a História. Belo Horizonte: Autêntica, 2008.

Rocha, Jose Justiniano da. Compendio de Historia Universal. Volume I: Historia Antiga. Rio de janeiro: Typ do Regenerador de Just. J. da Rocha, 1860.

Seignobos, C. H. Compendio da Historia da civilização - desde os tempos mais remotos até a atualidade. Traduzido por D. A. Cohen. Paris e Lisboa: Livrarias Amaud e Bertrand; Rio de Janeiro, São Paulo e Belo Horizonte: Livraria Francisco Alves, 1910.

Turin, Rodrigo. A Prudência dos Antigos: figurações e apropriações da tradição clássica no Brasil oitocentista. O caso do Colégio Imperial Pedro II. Anos 90 (Porto Alegre), vol. 22, n. 41, 2015, p. 299-320. 